\title{
Physicists rally behind linear-collider plan
}

\section{Colin Macilwain, Washington}

US high-energy physicists, gathered at a three-week meeting in a ski resort in Colorado, gave their backing to the idea that the construction of a large linear collider is the top priority for their discipline.

"There's widespread agreement that we should be pushing for a linear collider," says Chris Quigg, a theorist at Fermilab in Batavia, Illinois, and co-chair of the conference at Snowmass. The meeting has been organized by the American Physical Society every five years since 1982, and sets the agenda for the discipline in the United States.

Meeting organizers say that even physicists exploring other concepts for large physics machines - such as a muon collider or a very large hadron collider - now see a linear collider as the top priority. Alexander Chao, an accelerator physicist at the Stanford Linear Accelerator Center (SLAC) in California and co-chair of the meeting, says "a majority of people in these two camps would agree" that the linear collider comes next.

But this consensus among US physicists has a downside that was dramatically exposed during the meeting, which ran from 30 June to 20 July. It means that Fermilab is emerging as the most viable US site for the machine, even though Japan has been collaborating with SLAC for several years on the design, on the basis that it might be built in Japan or in California.

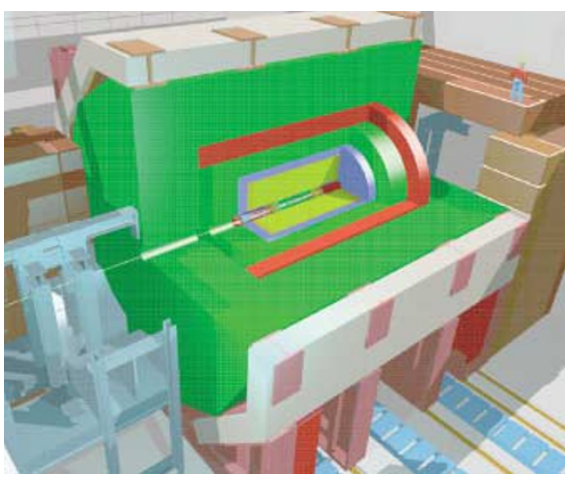

First in line: technology developed at DESY in Germany may be used in a new linear collider.

Hirotaka Sugawara, director of KEK, the Japanese high-energy accelerator organization, declared at the meeting that Illinois was an unsuitable site for the collider, and attacked SLAC for appearing to endorse consideration of its location there.

Physicists say Sugawara was angry because he has long suppressed the preference of some KEK scientists for a design that operates in one frequency band, in order to collaborate with SLAC on another.

Chao says there is no doubt that KEK felt betrayed by SLAC. He adds that "the rift between SLAC and KEK strengthens the case" for the technology being developed by Germany's high-energy physics laboratory, DESY (see Nature 410, 397; 2001).
Yukihide Kamiya, KEK's accelerator director, says Sugawara's comments were intended to encourage SLAC to continue pursuing a Californian site for the machine. SLAC's own site cannot accommodate the accelerator. "There is no change in KEK's policy, no change in our desire to collaborate with SLAC in the project," adds Kamiya.

In the past, some US physicists have expressed concern that the linear collider will be too expensive to build, and suggested that other ideas, such as a muon collider, might become their top priority. And many university physicists remain concerned about the impact of a large construction project on their grant funding.

But soundings at Snowmass, including an informal poll of the 1,200 attendees, found strong support from all segments of the community for the linear collider, whether it is built in the United States or elsewhere.

The High Energy Physics Advisory Panel, a group of scientists that advises the US Department of Energy and the National Science Foundation, is preparing a 20-year plan for the discipline, with an interim version of its report due in October.

"The community feels that high-energy physics needs a new facility, and the majority think that it should be a linear collider," says Barry Barish of the California Institute of Technology, co-chair of the advisory panel writing the report.

\section{Sea lions massacred in Galapagos for sex organs}

\section{Rex Dalton, San Diego}

About 25 sea lions in the Galapagos National Park were butchered for their sexual organs earlier this month, angering biologists who work to conserve them.

The mutilated sea lions of both sexes were found on the morning of 14 July on a beach on San Cristobal Island in an area near the airport where tourists go to view the island's diverse animal life. The sea lions had been clubbed in the head the night before, and their penises, gonads or ovaries cut out. Some of the animals were still alive when they were found.

Michael Bliemsrieder, a US-based biologist with the Charles Darwin Foundation, says sea-lion sex organs are sold in Asia for medicinal purposes.

This year's sea-cucumber harvest is under way in the islands' waters, attracting many foreign traders. Bliemsrieder says Ecuadorian authorities are investigating whether any of the traders were involved in the attack. There have been isolated attacks on sea lions during previous harvests, officials say, but nothing on this scale.

Paola Diaz, a spokeswoman for the Charles Darwin Research Station on the

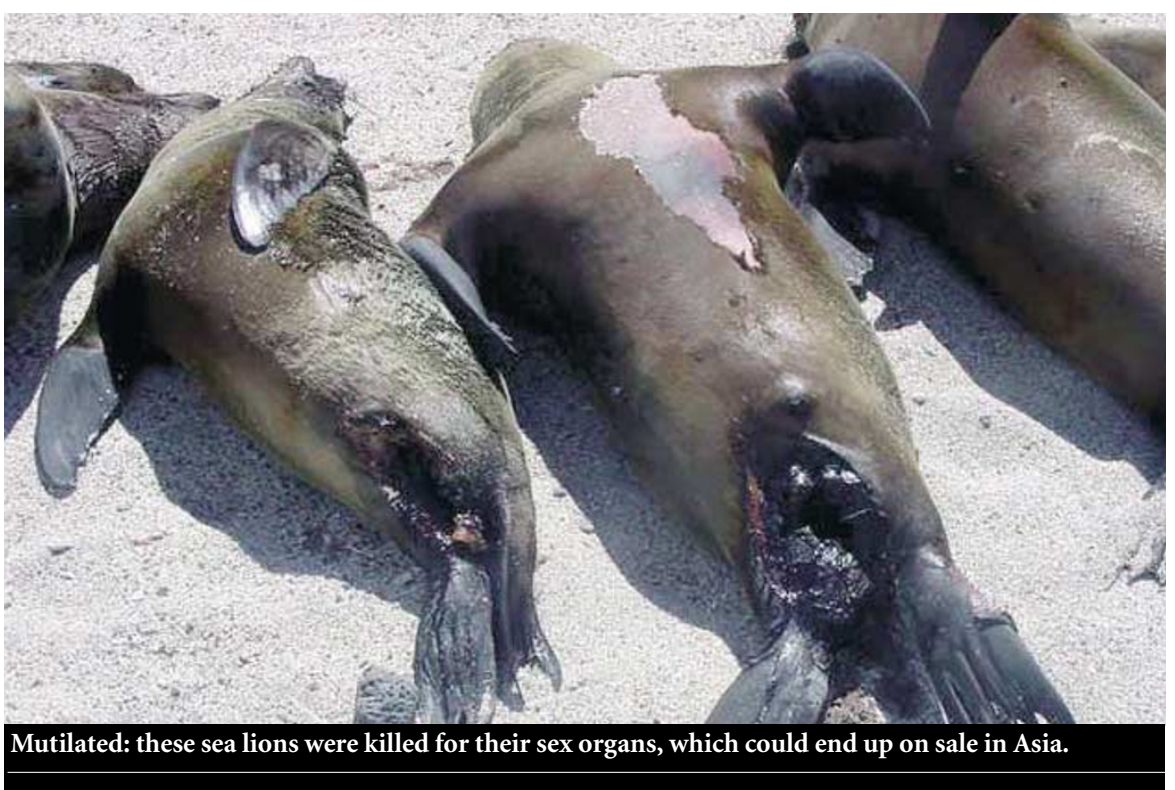

islands, says scientists and the community have raised around US\$5,000 for a reward for information leading to an arrest. 